\title{
The Study of the Effect of Urbanization on Urban-Rural Income Gap in Jiangxi Province
}

\author{
Yu Bing-wen \\ School of Economics, Jiangxi University of Finance and Economics \\ E-mail:yubingwen2005@163.com
}

\begin{abstract}
Urbanization is not only an important way to transfer the rural labor but also an efficient way to improve life quality. The text takes Jiangxi province as an example. It is based on the statistical data of Jiangxi province from 1978 to 2012 and makes a empirical study on the relationship between urbanization and the effect of urban-rural income gap. And the result shows that there is, indeed, a long-run equilibrium relationship among the two above, and to be specific, the improvement of urbanization is conducive to narrowing the income gap. And it is one of those significant ways to narrow the urban-rural income gap by speeding up the urbanization.
\end{abstract}

Keywords: urbanization, rural and urban income, gap

\section{Introduction}

There has been a rapid growth in Chinese economy and the living standard of its residents. The Gross Domestic Product has increased from 364.52 billion RMB to 51.93 trillion RMB in 2012. Meanwhile, the PCDI (per capita disposable income) of urban residents has increased from $343.4 \mathrm{RMB}$ to $24565 \mathrm{RMB}$ and the per capita net income of rural residents has also increased from 133.6RMB to 7917RMB during the same period. They have increased by 11.8 and 13.9 times respectively without considering the price change. However, achievements came with problems such as the continuous widening of the urban-rural income gap. The index of rural and urban income gap has increased from 2.57 in 1978 to 3.10 in 2012 which still tends to rise. The problem has a negative influence on the development of our economy. What's even worse, it could lead to some severe social problems like social stratification, the collision between urban and rural residents, etc. As a result, while developing the economy, we should also focus on the problem of income inequality.

In Jiangxi province, the problem of the urban-rural income gap is even severer, because of the slower development of its economy. Having the largest income gap in the central region, the index of urban-rural income gap has raised from 1.4 in 1983 to 2.5 in $2012,2.8$ at the maximum. Hence, the policy of "The central committee of the communist party of china on several major issues comprehensively deepen reform" in the third plenary session of 18 aimed to realize the harmonious development between medium cities and small towns, the industrial and urban integration development and the coordinated promotion of urbanization and the new rural construction. And the government work reports in this year also put the urbanization and the new rural construction as key tasks. So it's of great importance to have a good study on the factors of the urban-rural income gap in Jiangxi province so as to take efficient measures to solve the problem and to realize the rise the Central China. Right in this case, based on the statistics in Jiangxi province in recent 35 years and from the perspective of urbanization, the text tries to seek some helpful answers to narrow the urban-rural income gap. 


\section{Literature Review}

First, the policies and our system have been contributing to widening the income gap. John Knight, Li Shi and Lina Song (2004) both hold the opinon that Chinese policies and system has prevented the agricultural surplus labor from flowing to non-agricultural industries and cities, which leads to an unbalanced welfare system and the current situation of income inequality [1]. Cai Fang (2003) analyzed the problem of income gap by means of institutional economics and drew a conclusion that policies of cities are the main factors [2]. Zhou Shijun and Zhou Qin (2011) certified that the long-run preferential policies to cities directly lead to widening of the income gap by constructing the measurement model of urban and rural income and the Regression model. Second, the financial development also has a negative influence on income gap [3]. The economist, Chen Binkai and Lin Yifu (2013) from the perspective of the government development strategy, found urban-rural income gap continued to widen reasons are the government aims to encourage strategic priority to the development of capital-intensive sectors, resulting in a relative decline in the employment needs of the urban sector, thus delaying the process of urbanization, rural residents can not be effectively transferred to urban, so income gap are widen [4]. Clarke (2003), after studying the global data about the relationship between financial development and income distribution with other economists, believes financial development did widen the income gap [5]. Yao Yaojun (2005) certified that there was a long-term equilibrium relationship between financial development and income gap by constructing the model of VAR [6]. Hu Zongyi and Liu Yiwen (2010) also made a study in the way of nonparametric tests, the result of which showed that in the initial stage, there is a significant and positive nexus existing between financial depth and income gap, but in the advanced stage, there is a negative correlation between them [7]. Zhang Hongyan, He Qing and $\mathrm{Yu}$ Qian (2013) use VAR model analysis a long-term equilibrium relationship between development and urban-rural income gap between China's rural finance and rural finance development of China's urban-rural income gap is widening Granger cause, the income gap between urban and rural residents is because the outflow of capital and non-rural formal financial development is not enough [8]. Greenwood and Jovanovi (1990) the relationship between financial development and income distribution studies of its findings are consistent with the theory inverted U-shaped Kuznets. Third, with the development of the economy, the income of residents increase, and the income gap widens, too [9]. Zhang Luo and Fang Tianfang (2007) also analyzed the relationship between urban-rural income gap and economic growth by means of Cointegration tests and Ginger cause-effect test and believe that economic growth contributes to widening the income gap [10]. By using inter-provincial panel data from 1978 to 2008, connecting with theory inducing and empirical study, Zhang Jianhui and Qi Tao (2011), Mao Qilin (2011) verified that, between Chinese economic growth and urban-rural income gap, the relationship of the inverted "U" shaped Kuznets curve is really existed. The last opinion analyzed the urban-rural income gap from the view of human capital [11, 12]. HOU Feng-yun, FU Jie and ZHANG Feng-bing (2009), Chen Bingkai (2010) analyzed the relationship among the educational investment by government, human capital investment and the urban-rural income gap in China by Oaxaca-Blinder, and the conclusion shows that the key to the problem lies in the difference in the level of education. There was another study which had the almost identical. In 2003, combined with inter-provincial panel data from 1993-2010 [13, 14]. Yang Xiaojun (2013) investigated the influence of rural human capital investment. The result put that the increase of rural human capital investment, especially the investment of education, is conducive to narrowing the income gap. Besides, the better the 
economy is, the measure is more efficient [15]. The last other factors affect the income gap between urban and rural areas, such as Ming Lu and Zhao Chen (2004) from the estimation results of the provincial panel data from 1987 to 2001 show between urbanization to reduce the income gap between urban and rural statistically significant effect [16]. Wang Xiaolu and Fan Gang (2005) find factors of economic growth, income redistribution and social security, public goods and infrastructure, as well as factors regime of the income gap will have an impact to the gap of income between urban and rural areas [17].

In summary, most of scholars investigated the urban-rural income gap from the perspective of policies and system, financial development, economic growth and the level of education, etc, and provided a lot of reference for other economists for their further study, however, seldom of them probed into the problem from urbanization. In fact, a reverence does exist between urbanization and urban-rural income gap, which has always been neglected since a long time. The moderate urbanization helps to promote the living conditions in rural areas, as a result of which, more people are able to enjoy the public services. So, on one hand, urbanization could reduce the all sorts of problems due to the excessive concentration of big cities, such as some environmental problems like the hazy weather, therefore, could release the stress of big cities and living costs in big cities; and on the other hand, urbanization could improve the living standard in rural areas and promote the economic development. Besides, as the development of the primary industry is prior, while in the urban areas, the situation is on the contrary, thus, a reasonable proportion of industrial structure is significant to narrow the income gap. in this case, the text aims to investigate the urban- rural income gap from the perspective of urbanization and industrial structure by means of Cointegeration and ECM and provide some helpful references for the government departments to make relative polices.

\section{The Transmission Mechanism between Urbanization and the Urban-rural Income Gap}

Based on the existing papers and combined with the current situation of the economy in our country, it can be concluded that there are main these ways to solve the problem of income gap by means of adjusting the industrial structure. 1. The effect of dual economy structure. In the initial stage of the development of our economy, the government carried out the dual economy structure---the urban-rural segmentation to boost the economic growth, therefore, most of the resources were transferred to the industrial areas, as a result, the labor productivity of the primary industry has been much lower then that of the secondary and the tertiary industry. Besides, that also leads to an unbalanced situation of capital, technical innovation, etc. between urban and rural areas and the widening income gap. 2. The employment effects. Since the Reform and Opening up, the industrialization process has made it possible that the secondary and the tertiary industry create more employment opportunities, which attracted the rural surplus labor, meanwhile, the income of rural residents has also increased. 3. The effect of income distribution. The dynamic industrial structure calls for various production factors, which will have a influence on the income and its distribution. As the secondary and tertiary industry are more preferential, the problem of unbalanced development of industrial structure appeared, as a result of which, the income gap between urban and rural areas became even bigger. 4. The transformation of industrial structure. During this process, as the secondary and tertiary industry became more and more preferential, many rural residents who had worked on the primary industry had to face the problem of unemployment. The structural unemployment also leads to widening the income gap. 5. The effect of transference of the human capital. Although the flowing of the 
surplus rural labor is conducive to narrowing the income gap, the shortage of young workforce who is necessary for the rural development, undoubtedly, is unhelpful to narrow the income gap, or even worse. Above all, we have confirmed that adjusting the industrial structure does have an influence on narrowing the income gap, but how to do it better; we still need to make a further study.

The urbanization mainly has two effects on the income gap. On one hand, urbanization contributes to widening the urban-rural income gap. 1. The effect of dual urban and rural household registration system. The strict system carried out in our country has prevented rural residents from flowing to urban areas. In general, those wealthy farmers are more likely to be urban citizens than the poor ones, which make the unbalanced income situation even worse. What's more, wages and welfare in cities are much better than that in countryside and that result in the further widening of the income gap. 2. Industrial agglomeration effect. The migration expands the size of cities, which results in the Industrial Agglomeration. Hence, it promotes the efficiency of the industrial production and reduced the cost of production in cities, therefore, the income of urban residents increases. 3. capital investment effect. As rural residents flow to urban areas, the government has to invest more in the infrastructure construction and public services, which would reduce the capital that should have invested in the countryside. And sure, that makes the situation in the rural areas worse than before and so was the income gap. However, on the other hand, urbanization is beneficial to narrow the income gap. 1. The competition effect. With the process of urbanization, transferring the surplus rural labor creates more job opportunities for rural labors and that helps them to increase income as the payment in cities is much higher than that in countryside. 2. The feedback effect of capital. When those who work in the cities bring the capital accumulated to the countryside to invest in the agriculture and the infrastructure construction. By this way, the living conditions can be improved. In addition, the income increases. 3. The effect of adjusting the rural economic structure. With the process of urbanization, transferring the surplus rural labor creates more job opportunities for rural labors. Hence, there is a sharp increase of per capita land. The scale management and industrialization of the adjusting the industrial structure. On one hand, the urbanization will be accelerated because of the income gap, which will attract the rural residents to flow to cities. Because of the income gap, there is a big difference between urban and rural consumption structure. To be exact, urban consumption is much more than that in rural areas and urban residents tends to consume better ones. In addition, instead of those necessary items, durable consumer items and other items for entertainment and social intercourse have been the core commodities in our daily life. Thus, we have to shift the gravity of development from the primary industry to the secondary and tertiary industry.

\section{Data Sources and the Variable Definitions}

\subsection{Data Sources}

All the sample data in the text are based on "The Statistical Yearbook of Jiangxi Province" from 1978 to 2012. Now I will briefly explain some related variables in the text.

\subsection{The Definition of Variables}

\subsubsection{The Index of Income Gap (Theil)}

In the existing papers, many scholars, like Lu Ming and Chen Zhao measured the urban-rural income gap by analyzing the urban per capita income-rural per capita net 
income ratio. Many other scholars, like Wang Xiaolu and Fan Gang hold the opinion that the Gini coefficient is the basic tool to analyze the income distribution. However, the Gini coefficient is very sensitive to the income changes of middle group, which can't reflect the income gap well. But unlike the index above, the Theil index is sensitive to the changes of both groups (high and low income). Besides, Theil index can reflect not only the changes of income but also the changes of relevant population structure. Hence, the text will apply the Theil index proposed by Li Xiaoyu and Guo Wen in 2011 to measure the income gap. The index will be marked as Theil. The formula is:

$$
\text { Theil } l_{t}=\sum_{i=1}^{2}\left(\frac{p_{i, t}}{p_{t}}\right) \ln \left(\frac{p_{i, t}}{p_{t}} / \frac{z_{i, t}}{z_{t}}\right)
$$

\subsubsection{The Urbanization Rate ( $U r b$ )}

The urbanization rate is a key index of urbanization process. The urban population-permanent population ratio is generally seen as the index, which has been applied by Cheng Kaiming and Li Jinchang in 2007 to refer to the urbanization rate. Although Mao Qilin used to discuss the urbanization rate by means of non-rural residents-permanent population, the former index is more widely accepted, because there is the official data to verify that. The index is also applied in this text, which is marked as $U r b$.

\subsubsection{The Industrial Structure Index $\left(I s_{2}, I s_{3}\right)$}

Generally speaking, the industrial structure refers to the propotional relationship of national economy. The text will apply the ratio of the total production in every industry to GDP as an index. But compared with GDP in developed countries, the gap lies in the tertiary industry. So our country has to pay more attention the tertiary industry as we are striving to be a developed country. And the ratio of total production in the secondary and tertiary industry will be respectively marked as $I s_{2}$ and $I s_{3}$.

\section{Empirical Analysis}

Based on the statistical data in recent 35 years since the Reform and Opening up, the text applies the dynamic econometrical method to investigate the interaction between urbanization, industrial structure and the income gap.

\subsection{Unit Root Test}

Constructing the traditional econometric model has an intrinsic requirement for the stable time series data of the variable. Hence, initially, the test will have a unit root test on the Time Series to test the stationarity, and the result is as follow:

Table 1. The Result of the Unit Root Test

\begin{tabular}{c|cccc}
\hline variables & ADF & $5 \%$ ( critical value) & probability & conclusion \\
\hline Theil & 0.2674 & -1.9510 & 0.7577 & unstationarity \\
Urb & 0.4547 & -3.5485 & 0.9987 & unstationarity \\
Is2 & -1.7227 & -3.5485 & 0.7190 & unstationarity \\
Is3 & -2.4046 & -2.9604 & 0.1487 & unstationarity \\
D (theil) & -3.6701 & -1.9513 & 0.0006 & stationarity \\
D (urb) & -3.7043 & -3.5530 & 0.0361 & stationarity \\
D (is2) & -4.9060 & -3.5530 & 0.0020 & stationarity \\
D (is3) & -4.4029 & -2.9540 & 0.0014 & stationarity \\
\hline
\end{tabular}




\subsection{Co-integration Test}

As many variables are involved in the text, the Johansen Method would be applied to test whether there is a long-term equilibrium among the four variables. First we need to find out the most suitable Cointegration lag order number to make sure the reliability of the statistics. Under the condition of unconstrained VAR (p) model and based on many test criterions like LR, FPE, AIC, SC and HQ etc., we can make the conclusion that the best order of AR is the second-order lag, namely the $\operatorname{VAR}(2)$ model.

Second, by applying the software Eviews and the Johansen Cointegration test, we can get the conclusion:

Table 2. The Result of Johansen Cointegration Test

\begin{tabular}{cccc}
\hline Original hypothesis & eigenvalues & Trace test $(\mathrm{P})$ & The biggest eigenvalues $(\mathrm{P})$ \\
\hline$r=0$ & 0.7724 & $89.6352(0.0000)$ & $47.36899(0.0000)$ \\
$r \leq 1$ & 0.5935 & $42.2663(0.0011)$ & $28.8057(0.0034)$ \\
$r \leq 2$ & 0.3402 & $13.4606(0.0990)$ & $13.3056(0.0704)$ \\
\hline
\end{tabular}

From the form, we can know that, around the critical value of 5\%, there are teocointegration relationships among Theil, $U r b$, and $I s_{2}$. As the first one, which is decided by the Likehood ratio, is more concerned, the revised formula is:

$$
\text { Theil }=0.2595-0.65142 U r b+0.8791 I s_{2}+0.5288 I s_{3}
$$

From the formula we can know that the Coeffecient of Urbanization is -0.6512 , and it has a negative correlation with the urban-rural income gap, which means that it has a positive effect on narrowing the income gap. to be exact, when the Coeffecient of urbanization rises by $1 \%$, the income gap would be narrowed by $0.6512 \%$; otherwise, the increase in the production in the secondary and tertiary industry has a positive correlation with the income gap, namely, when the ratio of the production in secondary and tertiary industry to GDP rises by $1 \%$, the income gap would be widened by $0.8791 \%$ and $0.5288 \%$ respectively. Surely, it's a long-run equilibrium relationship. If a further study on this is wanted, the ECM is necessary.

\subsection{The Error Correction Model}

The result and formula of the cointegration test verified the long-term equilibrium relationship among the urban-rural income gap, urbanization, and industrial structure. But with the parameter estimation of ECM, we can find out not only the relationship, but also how the variables deviate from the equilibrium and the short-term interaction among the four variables. With Eviews, we are able to get the complete ECM.

$$
\begin{aligned}
& \Delta \text { Theil }_{t}=-0.4872 \mathrm{Theil}_{\mathrm{t}}+0.6512 \mathrm{Urb}_{t}-0.8791 I s_{2, t}-0.5288 I s_{3, t}-0.2595+ \\
& \left(0.4734 \text { Theil }_{t-1}+1.1997 U r b_{t-1}-0.1831 I s_{2, t-1}-0.2024 I s_{3, t-1}-0.0078\right)
\end{aligned}
$$

\subsection{The Impulse-response Function}

The Impulse-response function is used to measure the standard deviation impact of the random disturbance terms and the changing values of the endogenous variable. In addition, it can reflect the dynamic interaction among the variables. Here is the response of the effect on the income gap by the urbanization and industrial structure. 
Response to Cholesky One S.D. Innovations
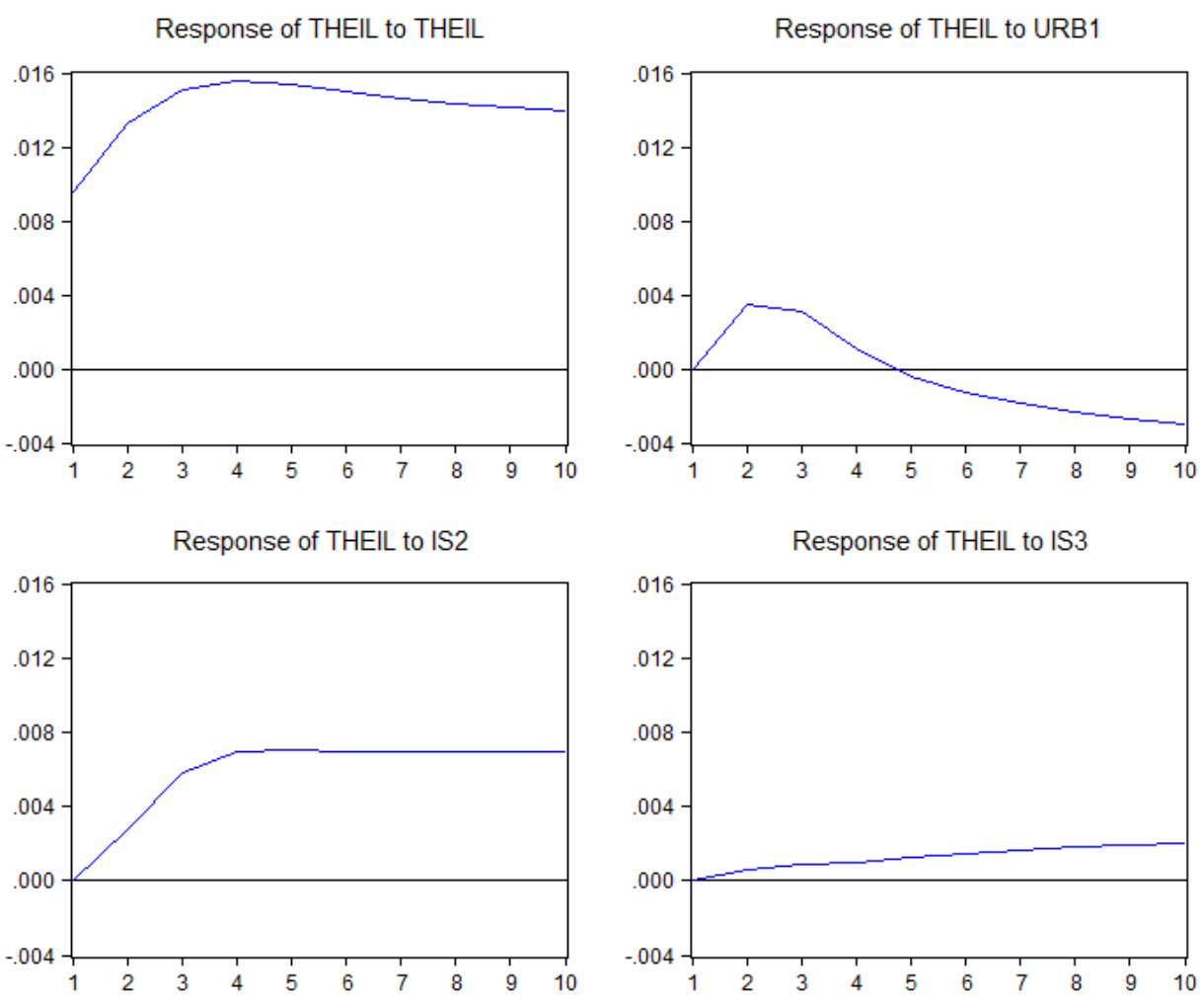

Figure 1. Response of Theil to Theil, Urb1, is2, is3

From the Figure 2, we can see that the urban-rural income gao is easily hit by itself. It increases rapidly in the first two periods. From the fourth period, it begins to decrease slowly. The urbanization rate, otherwise, starts to rise from the original point -0 , and reaches the maximum in the second period. After that, in begins to decrease until the fifth period when the urbanization rate is negative.

From the pulse influence function we can conclude that, at first, the change of urbanization rate has a positive effect on widening the income gap. After lasting a while, the effect turns into negtive, namely, the increase of urbanization would widen the income gap at first, then it has the opposite effect. What's more, the changes of the ratio of producyion in secondary and tertiary industry to GDP also has the positive effect on widening the income gap, which means that the income gap would be widened when the ratio rises. The impact effect on the income gap still doesn't have the tendency of approaching 0 in the 10th period. All in all, the urbanization and industrial structure has a long-term impact on the income gap, and the impact tend to be bigger and bigger.

\section{Conclusions and Suggestions}

\subsection{Conclusions}

Judging from the dynamic analysis of the relationship among urbanization in Jiangxi province and urban-rural income gap, we can come to following conclusions: First, there exist a long-term balanced relationship among urbanization and urban-rural income gap. Urbanization is negatively related with the income gap between urban and rural areas. Every $1 \%$ increase in the rate of urbanization will 
lead to $0.6512 \%$ decrease in urban-rural income gap; the second and third industry and the income gap between urban and rural areas were positively correlated. Second, when urban-rural income gap's short-term fluctuations deviated from its long-term equilibrium, it will be brought back to the balanced state at 0.4872 . Third, the impulse response analysis indicates that urbanization and industrial structure have a relatively long influence on urban-rural income gap. Moreover, this kind of influence is increasing constantly.

\subsection{Policy Suggestions}

Taking account of the conclusions above, this paper offers following policy suggestions.

First. In accordance with the overall development of national development strategy, we should implement urbanization vigorously. 1, the government should build a rational distributed urbanized system where big and middle sized cities can develop harmoniously with small cities. 2 , the government should accelerate the development of middle and small sized cities and put more attention to small towns, therefore create a well-distributed and harmonious situation where cities and towns can promote and supplement each other. 3 , regional cities have to be combined with towns to create an urban network to improve economic capabilities and socia efficiency.

Second. The policy of citizenization should be carried forward orderly combined with the current situation of undeveloped economy in central region. The most sever problem emerging in urbanization is that rural workforce are difficult to settle in cities. They are beyond the urban welfare system and in an unsecure and unprotected situation. With adjusting the industrial structure and upgrading industries, urban development requires more and more about rural labors. Nowadays, rural residents came to cities not only for the purpose of earning money in cities and consuming in countryside but also for the purpose of pursuing a city lifestyle.

Third. Supported by industries, urban areas need to improve the capabilities. Urbanization needs to be enriched by developing industries. In return, developing industries is helpful to create job opportunities. Meanwhile, urbanization can also provide a better platform for developing industries. Hence, the government should keep up developing cities and upgrading industries harmoniously and combine urbanization with instructing emerging industries, developing service industries and create job opportunities.

Fourth. The government should keep an eye on the "one-sided" urbanization. They should pay attention to some problems such as traffic congestion and environmental pollution. More efforts are required to protect ecology, improve dwelling circumstances and management services and promote the quality of urbanization. During the progress of urbanization, the fundamental way of land requirement lies in optimal and intensive land use, promoting land use rate in urbanization which means we can produce the largest economical, social and ecological benefits in the price of limited land.

\section{Acknowledgment}

This work was supported by the National Natural Science Foundation of China (Project No. 71261007).

\section{References}

[1] J. Knight, S. Li and L. Song, Editor, University of Oxford Press, Oxford, (2004).

[2] F. Cai, J. Social Sciences in China, vol. 5, no. 16, (2003).

[3] S. J. Zhou and Q. Zhou, J. Finance and Trade Economics, vol. 7, no. 29, (2011). 
[4] B. K. Chen and Y. F. Lin, J. Social Sciences in China, vol. 4, no. 81, (2013).

[5] R. G. Clarke, L. C. Xu and H. F. Zou, Z. World Band Policy Research Working Paper, vol. 2984, (2003).

[6] Y. J. Yao, J. Finance and Economics, vol. 31, no. 49, (2005).

[7] Z. Y. Hu and Y. W. Liu, J. Statistical Research, vol. 27, no. 25, (2010).

[8] H. Y. Zhang, Q. He and Q. Yu, J. Zhongnan University of Economics and Law, vol. 1, no. 83, (2013)

[9] J. Greenwood and B. Jovanovic, J. Political Economy. Financial Development, vol. 6, no. 98, (1990).

[10] L. Zhang and T. K. Fang, J. Agricultural Technology, vol. 3, no. 38, (2007).

[11] J. H. Zhang and T. Jin, J. Academic Monthly, vol. 43, no. 48, (2011).

[12] Q. L. Mao, J. ZheJiang Social Sciences, vol. 1, no. 11, (2011)

[13] F.Y. Hou, J. Fu and F. B. Zhang, J. Finance and Economics, vol. 1, no. 4, (2009).

[14] B. K. Chen, P. F. Zhang and R. D. Yang, J. Managment World, vol. 35, no. 36, (2010).

[15] X. J. Yang, J. Agrotechnical, vol. 4, no. 13, (2013).

[16] M. Lu and Z. Chen, J. Economic Research, vol. 6, no. 50, (2004).

[17] X. L. Wang and G. Fan, J. Economic Research, vol. 10, no. 24, (2005).

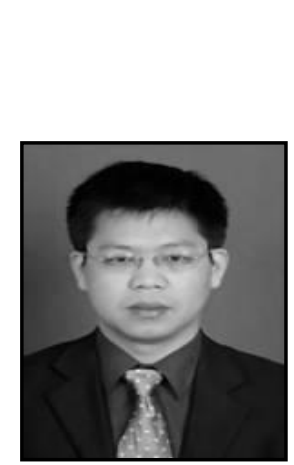

\section{Author}

Yu Bing-Wen, was born in 1974. He received the Ph.D. degree in school of business administration from Zhongnan University of Economics and Law, wuhan, China, in 2011. He is currently a lecturer in the school of economics at jiangxi university of finance and economics. He is the author or coauthor of fifteen papers published in international and local journals. His current interests include industrial economy, appraisal evaluation and real estate research. E-mail: yu_bingwen@sina.cn. 
International Journal of $u-$ and $e-$ Service, Science and Technology Vol.8, No. 7 (2015) 